\title{
Comparison of the surface roughness of feldspathic porcelain polished with a novel alumina-zirconia paste or diamond paste
}

\author{
Suparaksa YAMOCKUL ${ }^{1}$, Niyom THAMRONGANANSKUL ${ }^{1}$ and Suchit POOLTHONG ${ }^{2}$ \\ ${ }^{1}$ Department of Prosthodontics, Faculty of Dentistry, Chulalongkorn University, 34 Henri-Dunant Rd, Patumwan, Bangkok 10330, Thailand \\ ${ }^{2}$ Department of Operative Dentistry, Faculty of Dentistry, Chulalongkorn University, 34 Henri-Dunant Rd, Patumwan, Bangkok 10330, Thailand \\ Corresponding author, Niyom THAMRONGANANSKUL; E-mail: niyom.t@chula.ac.th
}

\begin{abstract}
This study compared the surface roughness of feldspathic porcelain polished with newly developed alumina-zirconia pastes or diamond paste. Porcelain discs were prepared and polished with sandpaper using a polishing-machine. The surface roughness (Ra) of each sample was measured using a profilometer. The samples were randomly divided into 6 groups $(n=10)$. The control group was polished with diamond paste (DP), and the five remaining groups were polished with the newly developed alumina-zirconia paste with the following ratios of glycerin:alumina:zirconia by weight: 1:0.5:0.5 (Z0.5), 1:0.5:0.75 (Z0.75), 1:0.5:1 (Z1), 1:0.5:1.5 (Z1.5), and 1:0.5:2 (Z2). The specimens were polished for $120 \mathrm{~s}$. The Ra values were determined again and the surface morphology of the porcelain samples was analyzed using SEM. The Ra values decreased as the amount of zirconia in the polishing paste increased, except for the Z2 group. The surface roughness as observed by SEM showed a correlation with the Ra values.
\end{abstract}

Keywords: Alumina, Dental porcelain, Zirconia

\section{INTRODUCTION}

Porcelain is widely used in dental restorations because of its esthetics, low thermal and electrical conductivity, ease of handling, and biocompatibility. In the dental clinic, porcelain restorations commonly need to be adjusted at their margins, contact areas, and contours. The dentist may need to remove the glazed surface of a porcelain restoration after cementation to perform occlusal adjustments, which alters the porcelain surface and can affect the neighboring teeth. An altered surface is rough and can cause dental plaque accumulation and staining, irritation of the gingiva and oral tissues, alter the esthetics of the restoration, and result in the deterioration of the opposing teeth. A previous study revealed a correlation between surface roughness and bacterial adhesion, and concluded that more bacteria adhered to a rough surface than to a smooth surface ${ }^{1)}$. Bollen et al. suggested that the tooth surface and any restorations should have a surface roughness $(\mathrm{Ra})$ value lower than $0.2 \mu \mathrm{m}$ and that this value is the threshold for bacterial adhesion ${ }^{2}$. Therefore, polishing and/or reglazing are necessary to restore the smooth surface of a porcelain restoration.

Many polishing methods can produce a surface as smooth as glazed porcelain ${ }^{3-5)}$. Al-Wahadni reported that rough porcelain surfaces polished with hybrid points, durawhite stones, ceramiste points, or diamond paste were not significantly different from that of glazed porcelain ${ }^{6}$. Bottino et al. found that there were no significant differences in mean $\mathrm{Ra}$ values between porcelain surfaces finished with a \#4138 diamond bur, polished with silicone rubber tips, and then with $6 \mu \mathrm{m}$

Color figures can be viewed in the online issue, which is available at J-STAGE.

Received Jul 4, 2015: Accepted Dec 15, 2015

doi:10.4012/dmj.2015-225 JOI JST.JSTAGE/dmj/2015-225 diamond paste on a felt disc, and glazed porcelain ${ }^{7}$. Sulik and Plekavich reported that there was no significant difference in surface roughness between polished and natural glazed porcelain ${ }^{5}$. Notably, Rosenstiel et al. showed that polished porcelain demonstrated a higher fracture toughness than that of glazed porcelain ${ }^{8)}$.

Polishing porcelain requires several steps to create a smooth surface. Dentists initially use diamond burs, tungsten carbide burs, steel burs, abrasive wheels, or separating discs to grind, reduce, or contour the bulk of the material. Fine and superfine burs or abrasive particles $8-20 \mu \mathrm{m}$ in diameter are subsequently used to finish the restoration, remove deep scratches, and smooth the surface. Finally, rubber abrasive points, fine-particle discs, and polishing pastes are used to polish the restoration, giving an enamel-like luster and shine to the surface ${ }^{9}$. According to previous studies, a polishing paste is required at the final step to polish a restoration ${ }^{6,77}$.

Polishing pastes are non-bonded abrasives that are dispersed in a water-soluble medium. They are used with a carrier device such as a rubber cup, buff disc, felt wheel, or bristle brush. Alumina and diamond are commonly used as the abrasive particles in commercial polishing pastes ${ }^{10}$. Zirconia is also used as an abrasive in industry and is found in $\mathrm{C}$ type silicone points (Shofu dental, Kyoto, Japan), which are used to polish composite resin ${ }^{11}$.

Zirconia is used in dentistry to manufacture single crowns and bridges, and consists of tetragonal zirconia polycrystals partially stabilized by the addition of three mole percent yttrium (3Y-TZP). Zirconia is available in block form; pre-sintered, partially sintered, and fully sintered blocks. During manufacturing, the block is milled in a milling machine, some of which remains 
after this process ${ }^{12)}$.

A porcelain restoration is typically polished and then re-glazed prior to cementation. However, after a restoration is cemented, only polishing can be performed. Therefore, selecting a suitable abrasive polishing paste is important, especially when polishing pits and fissures that cannot be polished using a bur, thus requiring polishing paste. The purpose of this study was to develop a new polishing paste containing zirconia leftover from the zirconia crown/bridge fabrication process that was as effective as a diamond paste when used to polish feldspathic porcelain. The null hypothesis was that the surface roughness of porcelain polished with aluminazirconia paste would not be significantly different from porcelain polished with diamond paste.

\section{MATERIALS AND METHODS}

\section{Specimen preparation}

Sixty-two feldspathic porcelain discs $(6 \mathrm{~mm}$ in diameter and $5 \mathrm{~mm}$ in thickness) were prepared by mixing porcelain powder (A3.5B vintage MP, Shofu) and distilled water on a glass slab and then placing the mixture in a silicone mold (Silagum-putty, DMG ChemischPharmazeutische Fabrik, Hamburg, Germany). The excess water was removed using blotting paper. The pre-fired specimens were removed from the molds and fired in a furnace (Programat P300, Ivoclar Vivadent, Liechtenstein) according to the manufacturer's directions. The porcelain discs were cooled in the furnace and each disc was embedded in a plastic pipe with epoxy resin (Fig. 1). An adhesive plastic template was used to standardize the position of the porcelain sample (inner circle) in the plastic pipe (outer circle) (Fig. 1A). The disc and plastic pipe were placed in their respective positions (Fig. 1B) and epoxy resin was poured into the pipe to fix their positions (Figs. $1 \mathrm{C}$ and D). After complete hardening of the epoxy resin, a registration mark was made at the bottom of the plastic pipe $(4 \mathrm{~mm}$ in width and $6 \mathrm{~mm}$ in depth) (Fig. 1E) to allow the specimen to be aligned at the same position during multiple roughness measurements.

The specimens (6 specimens/round) were polished for 5 min with 240-grit sandpaper (3M Wetordry abrasive sheet, 3M, MN, USA) by a polishing machine with an automatic head (Nano 2000 grinder-polisher with a FEMTO 1000 polishing head, Pace Technologies, AZ, USA). The application force used to polish the specimens was set at $2 \mathrm{~kg} / \mathrm{cm}^{2}$. The sandpaper rotated $100 \mathrm{rpm}$ clockwise and the samples rotated $100 \mathrm{rpm}$ counterclockwise. New sandpaper was used each round. The polished samples were then ultrasonically cleaned (CP360 Powersonic, Crest Ultrasonics, NJ, USA) in distilled water for $5 \mathrm{~min}$, then rinsed and dried.

The surface roughness ( $\mathrm{Ra}$ ) of the samples was measured using a profilometer (Talyscan 150, Taylor Hobson, Leicester, UK) to determine the baseline roughness. Five $2 \mathrm{~mm}$ measurements were taken at the center of the porcelain disc with a cutoff value of $0.25 \mathrm{~mm}$ and stylus speed of $0.5 \mathrm{~mm} / \mathrm{s}$. The vertical distance between each transverse measurement was $0.4 \mathrm{~mm}$. The sample was then rotated $90^{\circ}$ and the $\mathrm{Ra}$ was re-measured using the same procedure. The $\mathrm{Ra}$ measurements obtained were averaged to generate a mean Ra value per sample.

After the first surface roughness evaluation, the samples were randomly divided into 6 groups $(n=10)$ according to different treatments. The first group was polished with diamond paste (control group) and the five remaining groups were polished with the newly developed alumina-zirconia pastes whose compositions are presented in Table 1.

\section{Polishing paste preparation}

One polishing paste and two types of abrasive particles were used in the present study. Diamond polishing paste (Diamond paste, $1 \mu \mathrm{m}$ diameter diamond particles, Jota Ruthi, Switzerland), alumina particles (Alpha alumina powder, $0.3 \mu \mathrm{m}$ diameter particles, LECO, St. Joseph, MI, USA) and zirconia particles.

The zirconia particles were made by milling presintered zirconia blocks (Katana zirconia, Kuraray Noritake Dental, Tokyo, Japan) left over from the milling of zirconia crowns or bridges. The blocks were milled using a milling machine (Planetary Mill, Pulverisette 5, Idar-Oberstein, Germany) generating 0.05-0.2 $\mu \mathrm{m}$ diameter zirconia particles. The particle size was verified using a particle size analyzer (HELOS/BR with RODOS, Sympatec, Clausthal-Zellerfeld, Germany).

The morphology of the three types of particles was
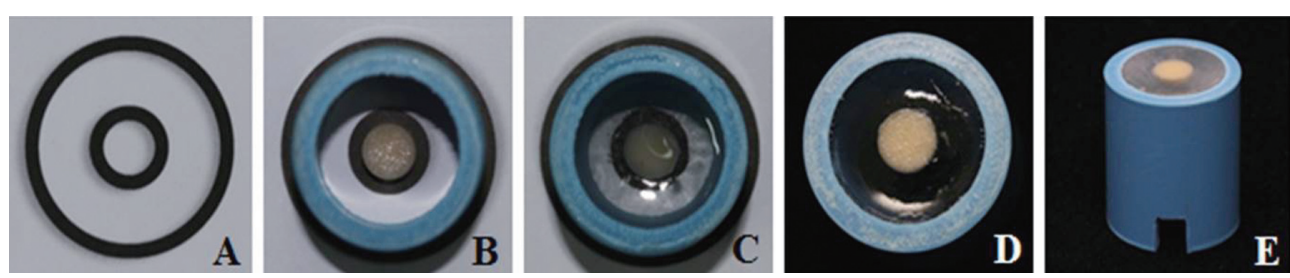

Fig. 1 Sample embedded in epoxy resin.

A) Adhesive plastic template to determine the position of the porcelain sample (inner circle) and plastic pipe (outer circle). B) The pipe placed over the porcelain specimen. C) Epoxy resin poured into the pipe. D) Sample embedded in epoxy resin. E) Embedded sample polished with sandpaper with a registration mark. 
Table 1 Polishing pastes used in the present study

\begin{tabular}{ll}
\hline Group & \multicolumn{1}{c}{ Polishing paste } \\
\hline DP & Diamond paste (control group) \\
Z0.5 & Alumina-zirconia paste (glycerin(1):alumina(0.5):zirconia(0.5) by weight) \\
Z0.75 & Alumina-zirconia paste (glycerin(1):alumina(0.5):zirconia(0.75) by weight) \\
Z1 & Alumina-zirconia paste (glycerin(1):alumina(0.5):zirconia(1) by weight) \\
Z1.5 & Alumina-zirconia paste (glycerin(1):alumina(0.5):zirconia(1.5) by weight) \\
Z2 & Alumina-zirconia paste (glycerin(1):alumina(0.5):zirconia(2) by weight) \\
\hline
\end{tabular}

studied using a scanning electron microscope (SEM). The SEM samples were prepared by dispersing the particles onto a glass slab that was fixed to an aluminum stub, and gold sputter coated (100 s, $50 \mathrm{~mA})$ using a sputtering device (Polaron Range SC7620 sputter, Quorum Technologies, UK). The particle images were taken using a field emission scanning electron microscope (JSM-7500F field emission scanning electron microscope, JEOL, Tokyo, Japan) with a $5-15 \mathrm{kV}$ accelerating voltage at 20,000 $\times$ and $75,000 \times$ magnifications.

When preparing the alumina-zirconia polishing paste, glycerin (Glycerol, Merck, Darmstadt, Germany) was used as the lubricant. Glycerin, alumina powder, and zirconia powder were weighed to within 0.0001 g using an analytical balance (GR 200, A\&D, Tokyo, Japan) according to the different groups' compositions and mixed using a plastic spatula for $5 \mathrm{~min}$. The mixtures were then loaded into syringes (1-0.1 mL scale) (Slip-Tip Disposable Tuberculin Syringe, Medline Industries, IL, USA).The polishing mixtures were used within one day.

\section{Polishing method}

Each polishing paste $(0.1 \mathrm{~mL})$ was placed onto the center of a porcelain disc that was then polished using a felt wheel (felt wheel, $22 \mathrm{~mm}$ in diameter, Jota Ruthi) on a micromotor (Micromotor and handpiece, Saeyang Microtech, Daegu, Korea) for $120 \mathrm{~s}$. Another $0.1 \mathrm{~mL}$ of the polishing paste was added every $30 \mathrm{~s}$. A new felt wheel was used for each group. All polishing procedures were performed by one operator. After polishing, the specimens were ultrasonically cleaned in distilled water for $5 \mathrm{~min}$, then rinsed and dried.

\section{Surface roughness measurement}

The surface roughness of the porcelain samples after polishing was measured using the profilometer as described above, with the samples placed at the same position as at the baseline roughness measurement.

\section{Scanning electron microscopy analysis}

Two specimens from each post-polishing group and two unpolished specimens whose $\mathrm{Ra}$ values had been measured were removed from the epoxy resin and ultrasonically cleaned in distilled water for $5 \mathrm{~min}$, then rinsed and dried. The SEM samples were mounted onto adhesive-coated aluminum stubs (1 sample/stub) and gold sputter coated as described above. The porcelain surface images were taken using a scanning electron microscope (Quanta 250 scanning electron microscope, FEI, OR, USA) with a $20 \mathrm{kV}$ accelerating voltage and $500 \times$ magnification to study the morphology of the porcelain surfaces.

\section{Statistical analysis}

The data were statistically analyzed using two-way repeated ANOVA followed by Bonferroni correction to compare the differences in mean Ra values between the groups at the 95\% confidence level (SPSS version 16.0 for Windows, SPSS, Chicago, IL, USA).

\section{RESULTS}

The SEM analysis of the particles revealed that the diamond (Fig. 2A) and alumina (Fig. 2B) particles were irregular in shape. In contrast, the zirconia (Fig. 2C) particles were relatively spherical. The differences in the sizes of the particles are apparent at higher magnification (Figs. 2 A2-C2).

The mean $\mathrm{Ra}$ values and standard deviation at baseline were $0.1036659 \pm 0.0018415$ (DP), $0.1032986 \pm 0.0029973 \quad(Z 0.5), \quad 0.1036784 \pm 0.0032501$ (Z0.75), $0.1038787 \pm 0.0026676$ (Z1), $0.1037793 \pm 0.0025419$ (Z1.5), and $0.1030514 \pm 0.0030287$ (Z2) $\mu \mathrm{m}$. There were no significant differences between the groups $(p>0.05)$. The mean $\mathrm{Ra}$ values and standard deviation after polishing for $120 \mathrm{~s}$ were $0.0458018 \pm 0.0018426$ (DP), $0.0537756 \pm 0.0034877 \quad$ (Z0.5), $\quad 0.0490913 \pm 0.0031607$ (Z0.75), $0.0415633 \pm 0.0025935$ (Z1), $0.0398272 \pm 0.0019766$ (Z1.5), and 0.0477830 $\pm 0.0007676(\mathrm{Z} 2) \mu \mathrm{m}$. The mean Ra value of each group after polishing was significantly lower than at baseline $(p<0.05)$. The significant differences between specific groups are shown in Fig. 3. The Z0.5, $\mathrm{Z} 0.75$, and Z2 groups had significantly higher mean Ra values than that of the DP group $(p<0.05)$. The Z1.5 group demonstrated the lowest mean $R$ a value and was significantly lower than that of the DP group $(p<0.05)$. There was no significant difference in mean Ra value between the $\mathrm{Z} 1$ and Z1.5 groups.

The surface roughness of the samples observed by SEM (Fig. 4) showed a correlation with their Ra values. 

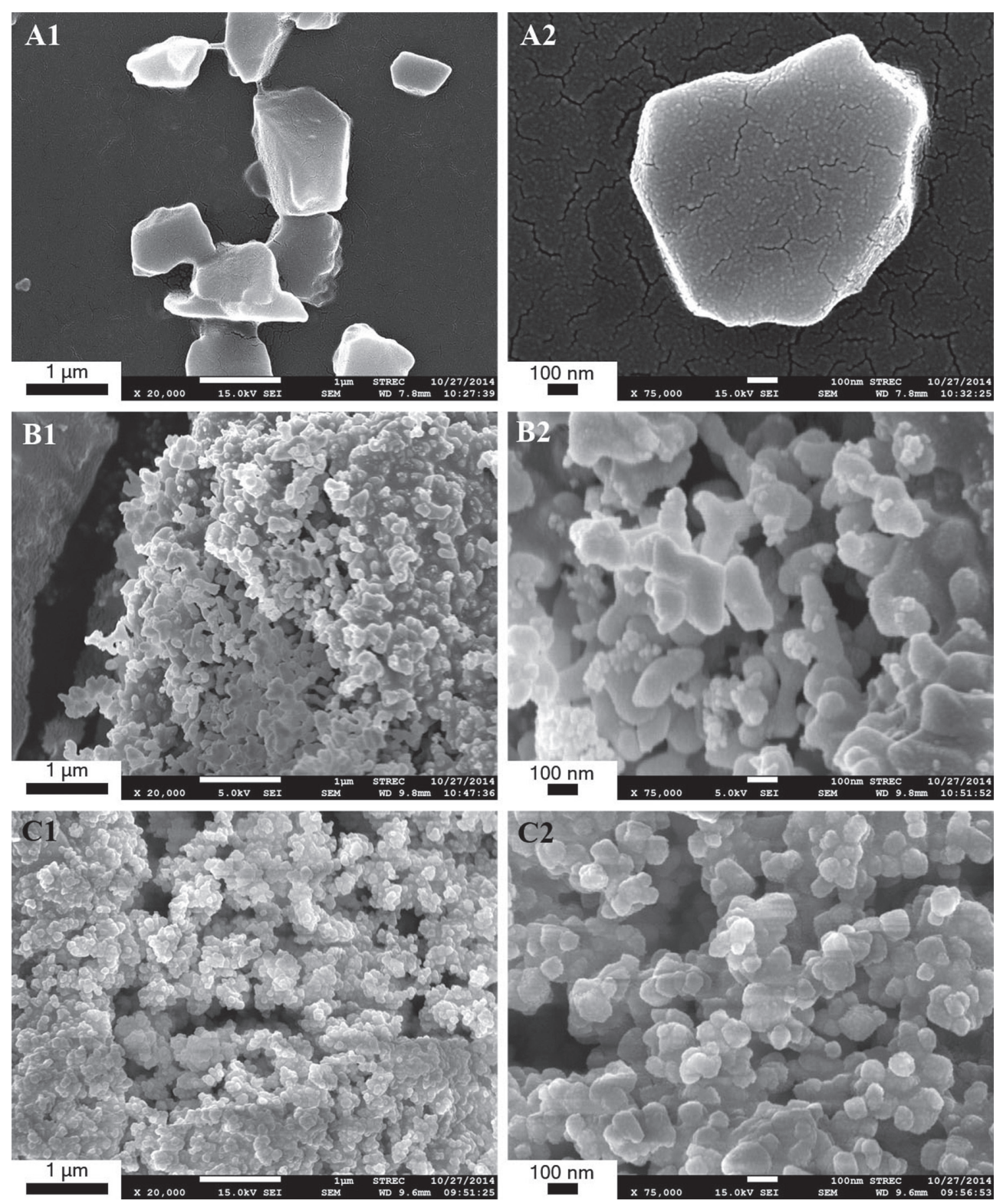

Fig. 2 Scanning electron microscope images of the polishing particles; A1) Diamond particles 20,000×, A2) Diamond particles 75,000×, B1) Alumina particles 20,000×, B2) Alumina particles 75,000×, C1) Zirconia particles 20,000×, and C2) Zirconia particles 75,000×.

The pre-polished discs showed the roughest surface (Fig. 4A). After polishing, the Z0.5 group demonstrated the roughest surface (Fig. $4 \mathrm{C}$ ) and the $\mathrm{Z} 1.5$ group had a homogeneous surface (Fig. 4F), compared to the other groups.

\section{DISCUSSION}

The present study investigated the effectiveness of a novel alumina-zirconia polishing paste compared to that of diamond paste in polishing feldspathic porcelain. The results of the present study indicated that the alumina- zirconia paste created a smoother porcelain surface and generated a significantly lower Ra value compared with diamond paste. Therefore, the null hypothesis was rejected.

The Ra values obtained with a profilometer are commonly used to describe the surface texture of porcelain samples. This value represents the overall roughness of a surface and provides quantitative information about the surface's texture. If this value is high, the surface is rough, while a low value indicates a smooth surface. Whitehead et al. suggested that when studying surface roughness, both quantitative 


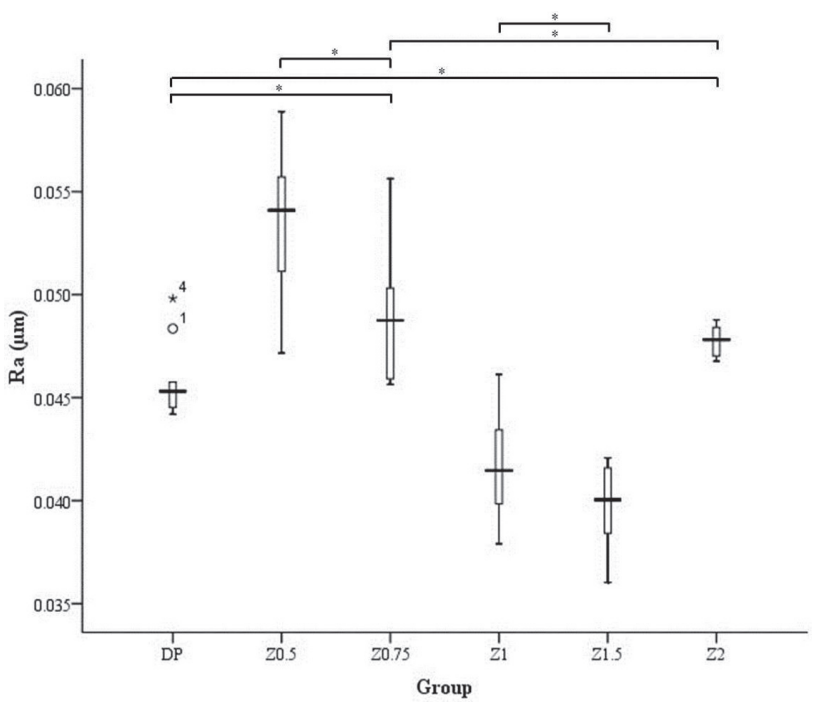

Fig. 3 Mean Ra values of the groups after polishing for $120 \mathrm{~s}$.

Asterisks (*) represent no significant difference between groups $(p>0.05)$ by two-way ANOVA and Bonferroni correction. and qualitative parameters should be evaluated ${ }^{13)}$. Therefore, in the present study, surface roughness was analyzed using a profilometer and SEM to generate quantitative and qualitative roughness data, respectively. The results of the present study indicated that there were significant differences in mean $\mathrm{Ra}$ values between the post-polishing groups. The $\mathrm{Z} 1$ and Z1.5 groups demonstrated the lowest mean Ra values and were significantly lower than that of the DP group $(p<0.05)$. Moreover, the SEM images of the polished discs showed a correlation with the Ra values. The Z0.5 group, which had the highest Ra value, demonstrated the roughest surface and the Z1.5 group, which had the lowest $\mathrm{Ra}$ value, had the smoothest surface. SEM analysis further revealed that every post-polishing group had a smoother surface than that of its respective baseline group.

Chairside porcelain adjustment and polishing are important restorative and prosthodontic procedures. Dentists often need to adjust the occlusion using diamond burs and then polish the restoration chairside with diamond paste. There have been many studies investigating surface roughness after the use of different
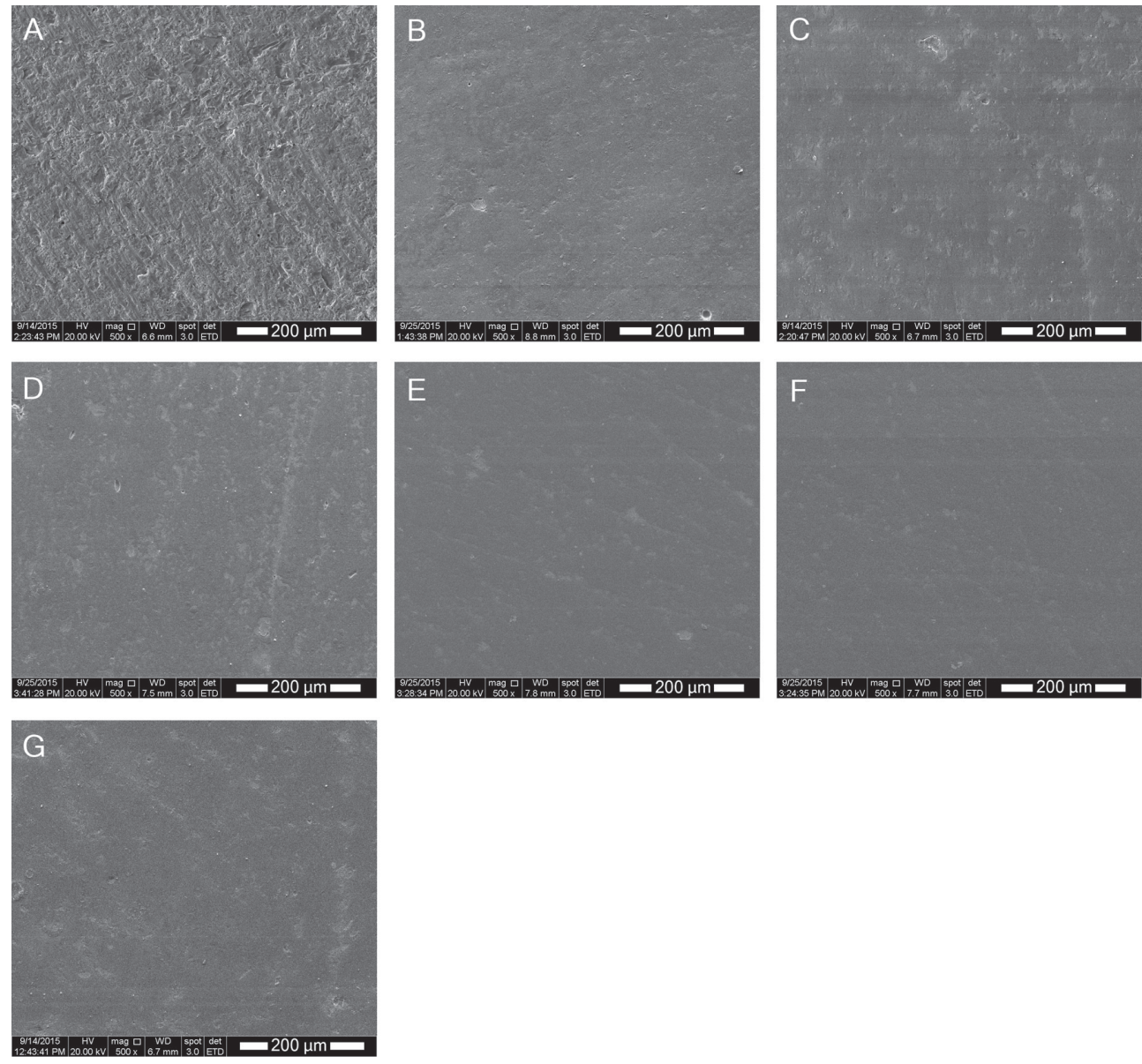

Fig. 4 Scanning electron microscope photographs (500×) of the porcelain surfaces polished with different polishing pastes; A: Porcelain surface before polishing with polishing paste, B: DP, C: Z0.5, D: Z0.75, E: Z1, F: Z1.5, G: Z2. 
surface polishing materials such as diamond paste, alumina paste, or zirconia paste ${ }^{3-5,7,14)}$. However, this is the first study evaluating a polishing paste combining alumina and zirconia particles.

Various polishing materials can be used to polish porcelain to obtain a smoothness comparable to glazing. Previous studies on the surface roughness of dental porcelain showed that very smooth surfaces were obtained when they were polished with diamond paste or alumina paste ${ }^{7,15-17)}$. A prior study suggested that polishing ceramic restorations with diamond paste at the final stage after clinical adjustment was equivalent to reglazing ${ }^{18)}$. In contrast, other studies have shown that final polishing with diamond paste, which is relatively expensive, did not significantly improve the surface smoothness of ceramic restorations ${ }^{3,15,16)}$.

A previous study found that using alumina or zirconia paste alone to polish porcelain did not create as smooth a surface as polishing using diamond paste ${ }^{14)}$. This finding corresponded with that of the pilot study. The mean $\mathrm{Ra}$ values of porcelain polished with diamond paste, alumina paste (glycerin(1):alumina(0.5) by weight), zirconia paste (glycerin(1):zirconia(0.5) by weight), and alumina-zirconia paste (glycerin(1):alumina(0.5):zirconia (0.5) by weight) were $0.0458018,0.0611444,0.0672184$, and $0.0537756 \mu \mathrm{m}$, respectively. Statistical analysis revealed that the $\mathrm{Ra}$ values of the post polishing groups were lower than the baseline values and there were significant differences between all groups $(p<0.05)$ (zirconia paste $>$ alumina paste $>$ alumina-zirconia paste $>$ diamond paste). These results indicated that porcelain polished with alumina or zirconia paste alone did not have as smooth a surface as porcelain polished with alumina-zirconia paste. Furthermore, porcelain polished with alumina-zirconia paste had a rougher surface compared with porcelain polished with diamond paste. Thus, the aim of the present study was to develop the optimum alumina-zirconia paste formulation that would be as effective or more effective than diamond paste. Zirconia was used as the main abrasive particles in differing amounts while the amount of alumina and glycerin remained constant.

The results showed that when the zirconia ratio in the polishing paste was increased to 1.5, a smooth porcelain surface was created, but when the ratio was increased to 2 , the porcelain surface was rougher. This may be because the alumina-zirconia paste at a ratio of 1:0.5:2 was too sticky and viscous and the paste could not adhere to the porcelain surface and spattered out during polishing. However, the present study did not focus on the viscosity of the polishing pastes. Therefore, further investigation is needed to evaluate this aspect.

A previous study has shown that polishing using abrasive particles much harder than the material, large sized particles, or irregularly shaped particles caused deep scratches on a material's surface ${ }^{19)}$. The ability of a polishing paste to polish a material is related to the surface hardness of the abrasive particles, which must be harder than the material to be polished. The Mohs hardness values of zirconia, alumina, and diamond are
8, 9, and 10, respectively. These hardness values are higher than that of feldspathic porcelain (6-7), thus, zirconia, alumina, and diamond particles can be used to polish feldspathic porcelain. Particle size is also related to polishing efficiency. Although larger sized particles can abrade a surface faster, they leave deeper scratches on the surface compared to smaller sized particles ${ }^{20)}$. Alumina powder $(0.3 \mu \mathrm{m}$ in diameter $)$ and zirconia (0.05-0.2 $\mu \mathrm{m}$ in diameter) were used in the present study. These particles are smaller than the 1 $\mu \mathrm{m}$ diameter diamond particles found in commercial products. Particle shape also influences polishing efficiency. Polishing using sharp or irregularly shaped particles leaves deeper scratches compared with round particles. In the present study, alumina particles, which are irregular, and zirconia particles, which are round, were used. This resulted in the porcelain surfaces polished with alumina-zirconia paste being smoother than those polished with diamond paste.

Polishing pastes consist of abrasive particles and lubricants such as water, water-soluble polymers, petroleum gels, or glycerin. Glycerin was used as the lubricant during the application of the abrasive because it is water-soluble, thus it can be easily cleaned off.

According to a previous study, there were no significant differences between using felt wheels, buff discs, or bristle brushes to polish porcelain ${ }^{21)}$. Felt wheels were used in the present study because a buff disc requires a large amount of polishing paste, and the paste would spatter out if a bristle brush was used.

A limitation of the present study is that it was an in vitro study and the efficiency of a polishing paste might be different under clinical conditions. Moreover, different results might be expected with different types of porcelain and polishing protocols. Further investigation is necessary to evaluate the surface roughness of other porcelain materials and other polishing protocols.

\section{CONCLUSION}

Our results indicate that polishing feldspathic porcelain with an alumina-zirconia paste with a ratio of glycerin:alumina:zirconia of 1:0.5:1.5 by weight results in a smooth surface. This polishing paste created a smoother porcelain surface and generated a significantly lower $\mathrm{Ra}$ value compared with diamond paste. Thus, an alumina-zirconia paste could be considered as an alternative to diamond paste in polishing feldspathic porcelain.

\section{ACKNOWLEDGMENTS}

This study was supported by a Chulalongkorn University Thesis Grant and the Faculty of Dentistry, Chulalongkorn University, Bangkok, Thailand.

\section{REFERENCES}

1) Aykent F, Yondem I, Ozyesil AG, Gunal SK, Avunduk MC, Ozkan S. Effect of different finishing techniques for 
restorative materials on surface roughness and bacterial adhesion. J Prosthet Dent 2010; 103: 221-227.

2) Bollen CM, Lambrechts P, Quirynen M. Comparison of surface roughness of oral hard materials to the threshold surface roughness for bacterial plaque retention: a review of the literature. Dent Mater 1997; 13: 258-269.

3) Fuzzi M, Zaccheroni Z, Vallania G. Scanning electron microscopy and profilometer evaluation of glazed and polished dental porcelain. Int J Prosthodont 1996; 9: 452-458.

4) Klausner LH, Cartwright CB, Charbeneau GT. Polished versus autoglazed porcelain surfaces. J Prosthet Dent 1982; 47: 157-162.

5) Sulik WD, Plekavich EJ. Surface finishing of dental porcelain. J Prosthet Dent 1981; 46: 217-221.

6) Al-Wahadni A. An in vitro investigation into the surface roughness of 2 glazed, unglazed, and refinished ceramic materials. Quintessence Int 2006; 37: 311-317.

7) Bottino MC, Valandro LF, Kantorski KZ, Bressiani JC, Bottino MA. Polishing methods of an alumina-reinforced feldspar ceramic. Braz Dent J 2006; 17: 285-289.

8) Rosenstiel SF, Baiker MA, Johnston WM. Comparison of glazed and polished dental porcelain. Int J Prosthodont 1989; 2: $524-529$

9) Anusavice KJ. Dental ceramics. In: Anusavice KJ, Shen C, Rawls HR, editors. Phillips' science of dental materials. 12th ed. St. Louis: Saunders Co; 2013. p. 419-473.

10) Jefferies SR. The art and science of abrasive finishing and polishing in restorative dentistry. Dent Clin North Am 1998; 42: 613-627.

11) Watanabe T, Miyazaki M, Takamizawa T, Kurokawa $H$, Rikuta A, Ando S. Influence of polishing duration on surface roughness of resin composites. J Oral Sci 2005; 47: 21-25.

12) Denry IL. Restorative materials-ceramics. In: Sakaguchi RL,
Powers JM, editors. Craig's restorative dental material. 13th ed. St. Louis: Saunders Co; 2012. p. 253-275.

13) Whitehead SA, Shearer AC, Watts DC, Wilson NH. Comparison of methods for measuring surface roughness of ceramic. J Oral Rehabil 1995; 22: 421-427.

14) Sarikaya I, Guler AU. Effects of different polishing techniques on the surface roughness of dental porcelains. J Appl Oral Sci 2010; 18: 10-16.

15) Haywood VB, Heymann HO, Kusy RP, Whitley JQ, Andreaus SB. Polishing porcelain veneers: an SEM and specular reflectance analysis. Dent Mater 1988; 4: 116-121.

16) Boaventura JM, Nishida R, Elossais AA, Lima DM, Reis JM, Campos EA, de Andrade MF. Effect finishing and polishing procedures on the surface roughness of IPS Empress 2 ceramic. Acta Odontol Scand 2013; 71: 438-443.

17) Wang F, Chen JH, Wang H. Surface roughness of a novel dental porcelain following different polishing procedures. Int J Prosthodont 2009; 22: 178-180.

18) Al-Wahadni A, Martin DM. Glazing and finishing dental porcelain: a literature review. J Can Dent Assoc 1998; 64: 580-583.

19) O'Brien WJ. Abrasion, polishing, and bleaching. In: O'Brien WJ, editor. Dental materials and their selection. Chicago: Quintessence Books; 2002. p. 156-164.

20) Antonson SA, Anusavice KJ. Materials and processes for cutting, grinding, finishing, and polishing. In: Anusavice KJ, Shen C, Rawls HR, editors. Phillips' science of dental materials. 12th ed. St. Louis: Saunders Co; 2013. p. 231-253.

21) Camacho GB, Vinha D, Panzeri H, Nonaka T, Goncalves $M$. Surface roughness of a dental ceramic after polishing with different vehicles and diamond pastes. Braz Dent J 2006; 17: 191-194. 